\title{
AicQoL2019Bali
}

http:/www. amerabra.org; $h$ ttps:/fspu.uitm.edu.my/cebs $7^{\text {h }}$ AMER International Conference on Quality of Life Wina Holiday Villa, Kuta, Bali, Indonesia 16-17 Feb. 2019

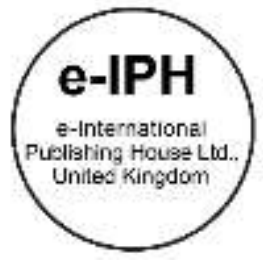

\section{The Application of Geographic Information System for Analysis of Using Pattern of Tha Pae Gate, Chiang Mai, Thailand}

\author{
Phichayapa Tammikakul ${ }^{1}$, Karuna Raksawin ${ }^{2}$ \\ 1 Graduate School Student, \\ 2 Associate Professor Dr., Faculty of Architecture, \\ Chiang Mai University, Thailand \\ ploplay_tawan@hotmail.com, karuna.r@cmu.ac.th \\ Tel: + 66869399375
}

\begin{abstract}
The article consists of two parts. The first part describes the GIS application to evaluate the appropriation to collect the using patterns in the public spaces. This part is the literature reviews of the related studies. In second part shows the procedures and results of GIS application which can be proofed the better benefit to collect the using patterns in term of data comparing and digital data collecting. The visualize spatial information is beneficial for the field of designers such as urban designers and landscape architects.
\end{abstract}

Keywords: Geographic Information System: GIS; Public Space; Public Square; Behavior, Tha Pae Gate

eISSN: 2398-4287 @ 2019. The Authors. Published for AMER ABRA cE-Bs by e-International Publishing House, Ltd., UK. This is an open access article under the CC BYNC-ND license (http:/creativecommons.org/licenses/by-nc-nd/4.0). Peer-review under responsibility of AMER (Association of Malaysian Environment-Behaviour Researchers), ABRA (Association of Behavioural Researchers on Asians) and cE-Bs (Centre for Environment-Behaviour Studies), Faculty of Architecture, Planning \& Surveying, Universiti Teknologi MARA, Malaysia. DOI: https://doi.org/10.21834/e-bpj.v4i10.1615

\subsection{Introduction}

Public Square is commonly in the heart of a traditional town, used as a space for community gatherings and a variety of activities for people within the community. The mentioned activities can take an essential part in the local community developments. Besides being used as the space for various activities, the public square can also indicate the identity and meaning of the town which is related to the living condition of its people. Moreover, the concept of a public square utilization concerns to the activities happening within the space. It can be achieved by understanding the necessities and needs of people within the community towards space, to meet the needs of users effectively, to express the identity of the area itself and to impress those who utilize the space. Therefore, it is highly essential and practical to conduct public square usage behavior survey to understand the user behavior pattern formed by the usage of people within the area.

The purpose of this research is to utilize the Geographic Information System (GIS) as the tool to collect the data of public square usage behavior. The initial step was to create the area map using geographical coordinates of Tha Phae gate square, combined with field surveys to ensure the accuracy of user data collected by the tools. Then, divide the gathered user data into different time intervals according to all coordinates of the users collected by GIS tool from the previous step. The final step was to process all received data with the computer software called ArcGIS10.1. The result of the process by the software was highly positive. It means that the software

eISSN: 2398-4287@ 2019. The Authors. Published for AMER ABRA CE-Bs by e-International Publishing House, Ltd., UK. This is an open access article under the CC BYNC-ND license http:/creativecommons.org/licenses/by-nc-nd/4.0). Peer-review under responsibility of AMER (Association of Malaysian Environment-Behaviour Researchers), ABRA (Association of Behavioural Researchers on Asians) and cE-Bs (Centre for Environment-Behaviour Studies), Faculty of Architecture, Planning \& Surveying, Universiti Teknologi MARA, Malaysia. DOI: https://doi.org/10.21834/e-bpj.v4i10.1615 
"ArcGIS10.1" can be used to process public square usage behavior pattern from the collected data. The result could also apply for further analysis in any future related researches.

The Tha Phae Gate is at the east side of the city walls, and it is one of the oldest gates in Chiang Mai, located in the East of the city canal. At present, Tha Phae gate has an open space across the city canal into Chiang Mai old town, the open space created in BE 2528 when renovated the Chiang Mai Gate, to arrange the activities in Chiang Mai (Yupparaj Wittayalai School, BE 2548). At present, this area is an assembly spot which is popular among tourists. The plaza is a big open space that has the identity of Chiang Mai which makes many activities emerged within this place (Madanipour, 1996), for examples, the walking street, public grouping for symbolic expression and the installation. Besides the activities mentioned, this area is frequently used in other activities as well which leads to this study subject.

In these days, this space is the center and the tourist spot of Thais and foreigners as it is an open public space which allows people access and join activities that have been arranged there (Madanipour, Ali, 1996). During the recent 3-4 years, Chinese tourists come to travel. Regarding the Department of Tourism, its information indicates that, during 2014-2015, the tourism rate in Chiang Mai dramatically increases. In 2016, the growth rate was $12 \%$, and the Tha Phae gate is one of the most historic spots for tourists. It is the reason why the author is interested in selecting the court at Tha Phae gate as the study site to examine the volume of users and how the activity occupies plaza because this popular site allows free access by walk.

The objective of this study is to experiment with the GIS system to gather information about the usage behavior of public space under behavioral study about human and environment. The study process starts with making a chart of the study area and Tha Phae Gate yard along with the geographical reference and field research. The data collecting process divided by period in a day and will be analyzed with the GIS system and other physical information such as the location of trees, chairs, and accesses from common routes, together with the pros and cons of the GIS system analysis for the adaptation in further study.

\subsection{Literature Review}

\subsection{Geographic Information System: GIS}

GIS is a geographic information system (GIS) for working with geographic information and maps. GIS can visualize spatial information. It offers a quick data collection. The creating and using maps, compiling geographic data, analyzing mapped information, sharing and discovering geographic information, using maps and geographic information in a range of applications, and managing geographic information in a database. (Refaat, 2007). GIS would also allow viewing, questioning, understanding, visualizing and interpreting the data into many ways which will reveal relationships, trend, and patterns in the form of charts and reports. The system provides an infrastructure for making maps and geographic information available throughout an organization, across a community, and openly on the Web. The GIS system is the operation of a spatial data computer system related to the spatial position in table or database form (Jirakajohnkool, 2008). This system is designed to collect, analyze and present geographical information by researching databases such as area and amount, then overlay this information on the geographic location, satellite aerial photo and map, which must have GEO reference/GEO code.

The GIS system is a valuable tool that benefits information storage. Nowadays, the GIS system development is in hardware and software which make the system simple to use. The analyzing process required information preparation, selection and also plan to keep the information up to date and valid to be used in future research. Behavioral Maps and GIS in Place Evaluation and Design (Marušić, 2012), considered the importance of human behavior to the area by analyzing the GIS. The primary analysis of behavior pattern can show the result of other response by the scope of time, density, clustering and distributing of the case study in Edinburgh (UK) and Ljubljana (Slovenia). The GIS will be used to connect behavior to the context but cannot be used to analyze the weather condition.

The Application of Geographic Information System for Construction Management (Bangnarong, 2017), the research use the GIS system to be a tool to gather and analyze information of Housing Project to sort out for presentation. The results can be used to track the construction process more comfortable and can be adapted to use in a more significant construction project. The Saransiri house project study has seven types in which the ArcGIS program functions to analyze the process and display each step of the construction process. Together with Google Sketchup program that shows a 3D image. This case study has a forewarning in information analysis error created by the geographic reference that required the field study research to verify the correctness of the information.

The Applied GIS in County-level City Plan, Bangkok: case study Bang Ruk, Ratchathewi and Phaya Thai (Mahawan, 2018). The research mention about planning and developing an enormous amount of information together with various information sources that required information technology to generate a physical plan. There are three steps in the process,

1. Field study information gathering

2. Information gathering

3. Analyze the information with information technology.

These steps show the benefit of information gathering with information technology. This research also indicates that the information related to the city plan and development plan nowadays is collected in various units which have their database and data analyzing process. Some info has never received from any group at all so that the information gathering in the same system is necessary to make the most benefit from the GIS. If the GIS system does not have enough data or has no data at all, there will be a high-quality tool but inefficiency. The most important thing is to make all information from all sources to be in the same database are references. After a 
study about applying the GIS system with the planning process and development plan, the result shows that all limitations solved and also reduce the processing time. It will make a plan and development plan can apply to the current situation which changes promptly.

Case study Japan: GIS-technologies in urban planning (Charles, 2017). This research used information technology in the development process and adjusted the city plan in Japan to make the city plan up-to-date. The GIS system used to gather and analyze data. The maps generated from the GIS system will compare to the current chart. The result from the GIS system shows the overall image of the city, height limit area, and commerce area. These data will benefit the future development process.

The adaptation if GIS system for making database about buildings with historical value in Phuket (Sitachitta, 2007). The research uses the GIS system to generate a database of buildings in Phuket. There are two parts of information, building information, and historical building information. The historical building information contains 401 valuable buildings. The information structure divided into four groups; building types, building's cultural value, building originality and building's status and threats. The historical building information structure contains 12 units; monument, bridge, roundabout, mausoleum, and court. The formation structure is similar to the historic building. It shows that the use of information technology to analyze city development plan make the process more efficient, information can be overlaid and adjustable.

From examples mentioned above about the GIS system can be concluded that it is an efficient tool which is suitable for the process and makes the process organized systematically. The convenience occurs from the process make the research process more manageable, make the information always up-to-date and can use as a future database. So that the researcher used the GIS system for the information gathering process in public yard usage behavior.

\subsection{Methodology \\ 3.1 Procedures in Research}

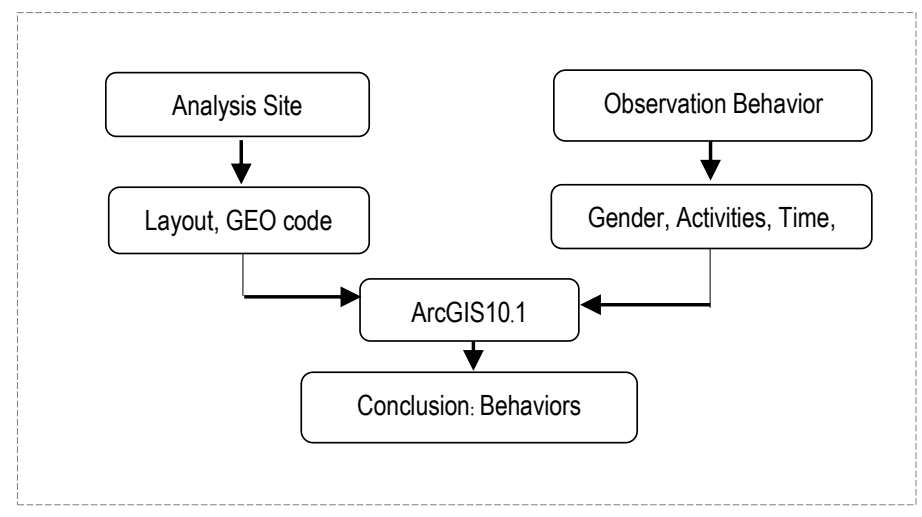

Fig.1: Steps of Research

This research is under the behavior study and activities that happened at Tha Phae Gate yard by using the GIS system to gather information to survey about how the plaza using were held and are the tool used suitably. This survey divided by a scope of time by records information every half an hour due to the changes of activities that happened mostly in 20 minutes. Also, to check whether the GIS system is suitable to the process by the ability to gather and display information together with the ability to reduce processing time.

\subsection{Program}

Surveying the Tha Phae gate to generate plan by the AutoCAD2017 program referring to the UMT (Universal Transverse Mercator Grid zone destination) then add the information to ArcGIS 10.1 program to scope the display area. The collecting process of the activities used the high angle shooting and stop motion by time scope divided. Then use the Google Earth Pro to find coordinates and fill the information into Microsoft Excel 2010 program and analyze with ArcGIS 10.1 program.

\subsection{Observation Mapping}

Field research at Tha Phae Gate yard in Chiang Mai to create area map by referring to coordinates and aerial photo from Google Earth Pro has an error in the location of the trees. It makes the researcher has to redo the field survey process to fix the problems that occurred. The result can be displayed with ArcGIS 10.1 program and set UMT coordinates which can reference with Google Earth Pro program. 


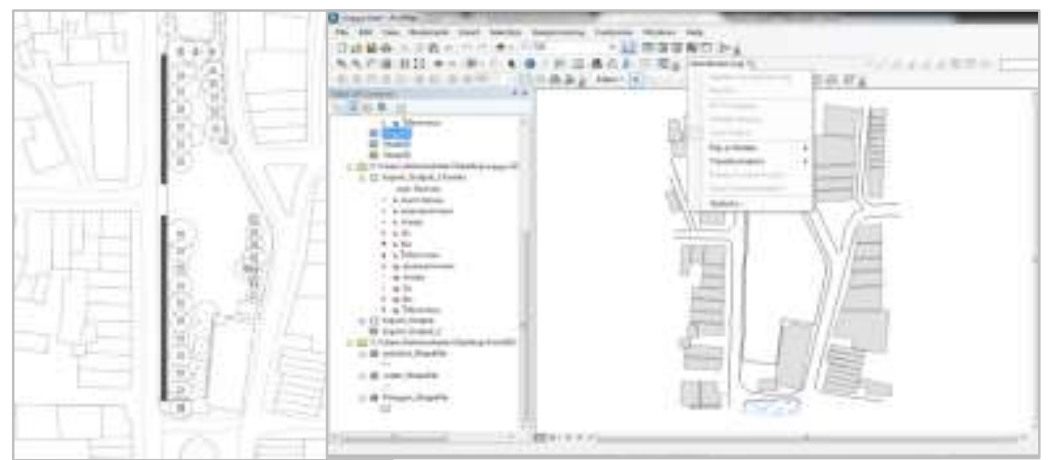

Fig.2: create the plan on ArcGIS10.1 which can be referred by Google Earth Pro.

The behavior observation process divided by gender and type of activity, substitute with symbols and capture with a camera to mark the position in the Google Earth Pro program then fill the information in Microsoft Excel table. (fig 3) ig.3: Mark and indicate the location on Google Earth Pro and record the data on Excel.

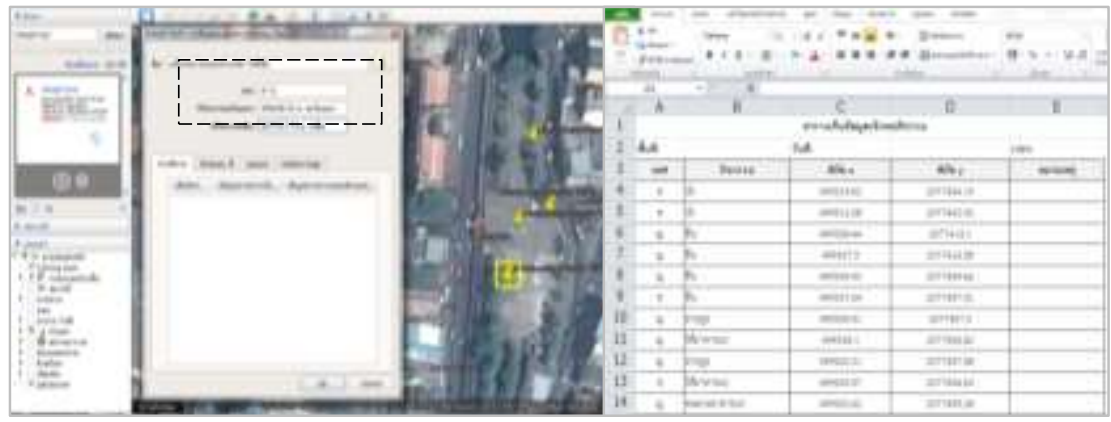

Fig.3: Mark and indicate the location on Google Earth Pro and record the data on Excel.

Then fill the information in the table to ArcGIS 10.1 program and set symbols that substitute gender and activity happened in the area which will make the result displayable. The set of information divided by the scope of time and displayed in the individual layer, and after substituted with symbols, the analyzing process begins. Moreover, the GIS system can reveal that it is an efficient tool which is suitable for the operation and makes the process organized systematically.

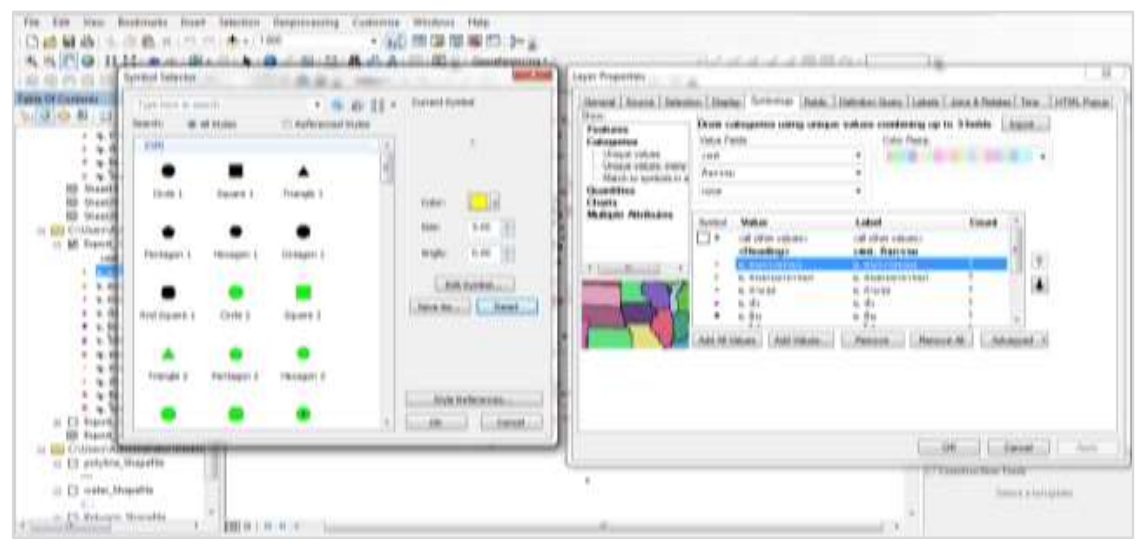

Fig.4: ArcGIS10.1: demonstrates the results of users in the forms of symbols and colors.

Geographic Information System (GIS) is the tool to collect data of user behavior in the public space. The study started from arranges the site plan which is the Tha Phae gate court in Chiang Mai, referring by geographic coordinate system and observation at the field study to verify the data and collect data from users. The data collection separated time duration. The results will be accurate to the coordinates mentioned above, display the symbols and colors clearly to make the distribution pattern noticeable. Furthermore, the result can be chosen to view individually or overall by the information layers. The resulting accuracy depends on the coordinate's exactness which required an examination to be most exact as possible to prevent any error. 


\subsection{Findings}

\subsection{Analysis of user behavior in the public space, site study, the Tha Phae gate in Chiang Mai Province by ArcGIS10.1}

The idea of public area usage should consider the activities which can be the usage patterns and the city symbolic (Carr, 1992). The Tha Phae gate yard is one a remarkable place which is popular among tourists. The researcher interested in behavioral research in the area and divided the survey time into three periods;

$\begin{array}{ll}\text { Morning; } & \text { 08:00 }-11: 59 \\ \text { Afternoon; } & 12: 00-15: 59 \\ \text { Evening; } & 14: 00-18: 00\end{array}$

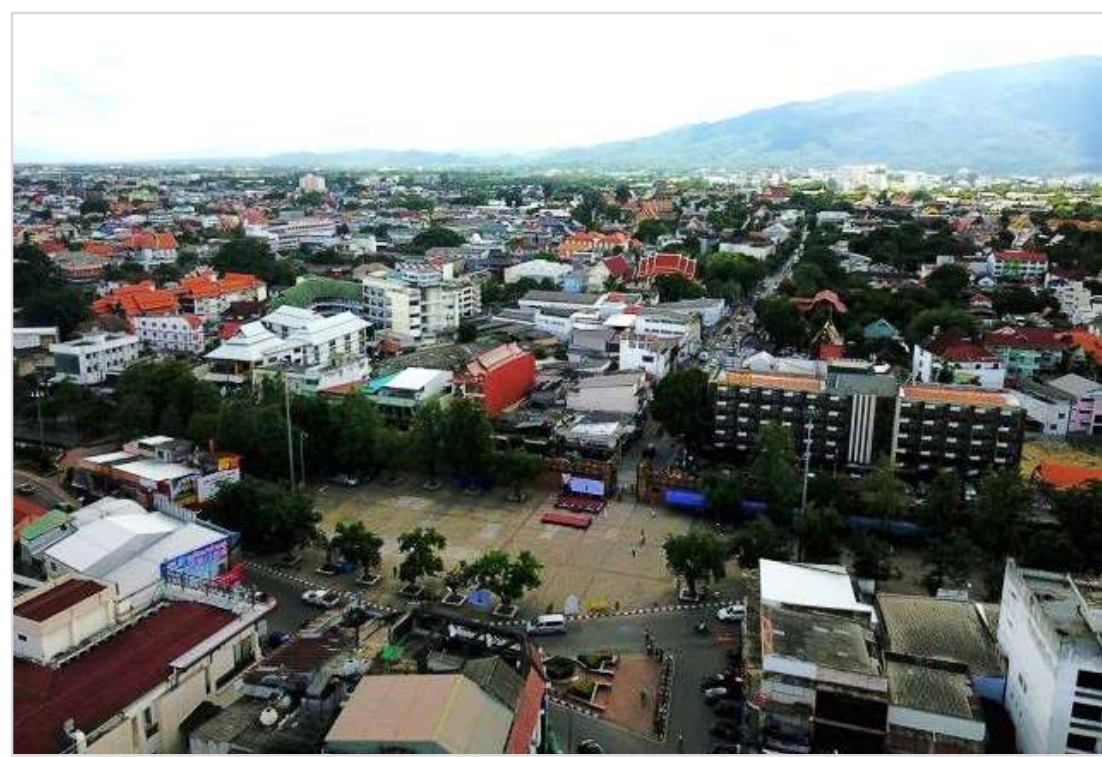

Fig.5: Top view of Tha Phae gate in Chiang Mai City, Thailand.

The information recording process will be every half an hour by the reason that most of the users tend to use the area more than 20 minutes per activities. The result shows that each day the activities that happened in almost every period are taking photos, feeding pigeons, resting, walking, open sells, music performances, pre-wedding pictures and any special events such as an assembly point for bicycle and motorcycle riders. The primary users of the area most are tourists especially Chinese tourists. The local people in the area mostly sell birds food, and the cleaner will clean the area regularly.

The report will use symbols divided by activities and genders to differentiate each activity from others and use the color codes for divide gender as follows, (Fig: 6 )

\begin{tabular}{lll} 
Male, Clean the floor & Female, Clean the floor \\
Male, Sell the pigeon food & Female, Sell the pigeon food \\
Male, Take a photo & Female, Take a photo \\
\hline Male, Sitting & Female, Sitting \\
\hline Male, Standing & 0 & Female, Standing \\
Male, Feed the pigeon & Female, Feed the pigeon
\end{tabular}

Fig.6: Symbol of activities 
In regards to the result as mentioned above, the conclusion is that the one-day activities at the Tha Phae gate are because it is the center of tourists. The result shows that overall users each day is around 596 people, both Thais and Foreigners. Women come to use in the area more than men in every moment. The main activity is taking a photo, relaxing and feeding the bird - special activities such as pre-wedding photo, riding bicycle and motorcycle. The local people usually are bird food sellers and cleaners. Detail displays in the table below. (table: 1)

Table 1: The total number of users for one day

\begin{tabular}{lcccccc}
\hline \multirow{1}{*}{ Activities } & \multicolumn{2}{c}{ Moring } & \multicolumn{2}{c}{ Afternoon } & Evening \\
\cline { 2 - 7 } & Male & Female & Male & Female & Male & Female \\
Feed the pigeon & 19 & 23 & 16 & 18 & 19 & 26 \\
Ride the bicycle & 4 & 4 & 0 & 0 & 2 & 0 \\
Sell bird's food & 4 & 8 & 3 & 4 & 2 & 4 \\
Take a photo & 21 & 36 & 20 & 19 & 29 & 34 \\
Sitting & 25 & 28 & 16 & 25 & 21 & 33 \\
Standing & 25 & 23 & 15 & 24 & 12 & 21 \\
Clean the floor & 3 & 0 & 1 & 0 & 0 & 0 \\
Motorcycle * & 5 & 0 & 0 & 0 & 0 & 0 \\
Pre-wedding * & 2 & 2 & 0 & 0 & 0 & 0 \\
& 108 & 124 & 71 & 90 & 85 & 118 \\
\hline & 232 & \multicolumn{7}{c}{161} \\
\hline total & \multicolumn{7}{c}{596} \\
\hline
\end{tabular}

Activity types display in the chart below, (fig 7-9)

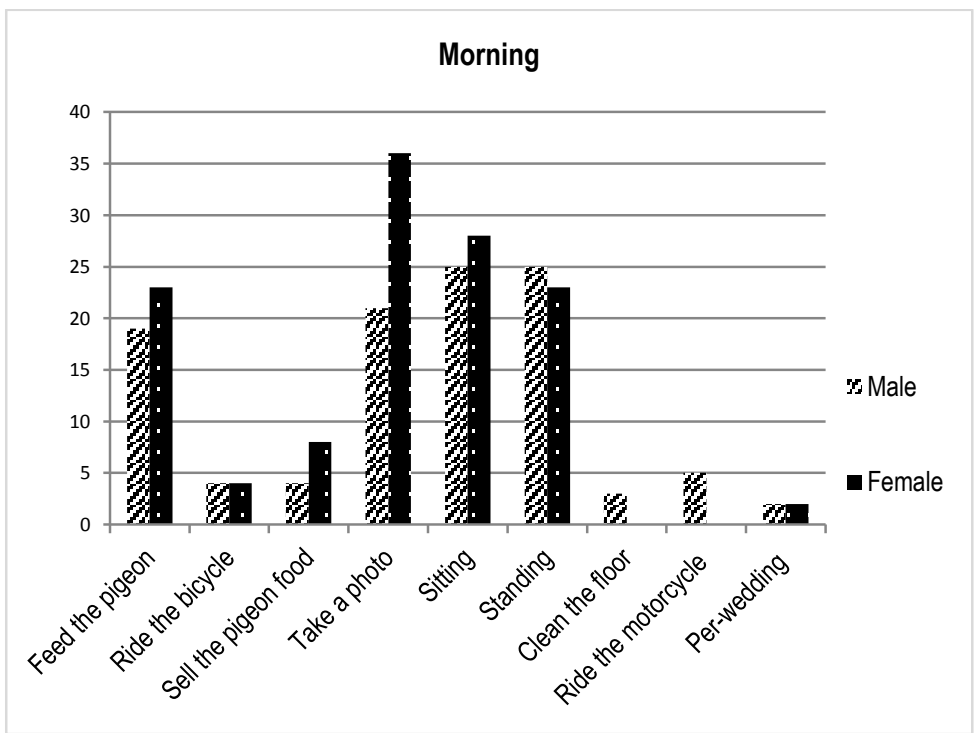

Fig.7: Diagram of morning usage during 8.00 a.m.-11.59 a.m.

The chart shows that from 08.00 - 11.59, there was 232 users, 105 males, and 124 females, the most done activity is taking the photo then resting and feeding pigeons respectively. The full duration is between $9.30-10.30$. Due to the weather, that is not too hot, so that the users tend to be using the area for movement activities at this time. Special events such as pre-wedding photo and bicycle rider's assembling sometimes happened. 


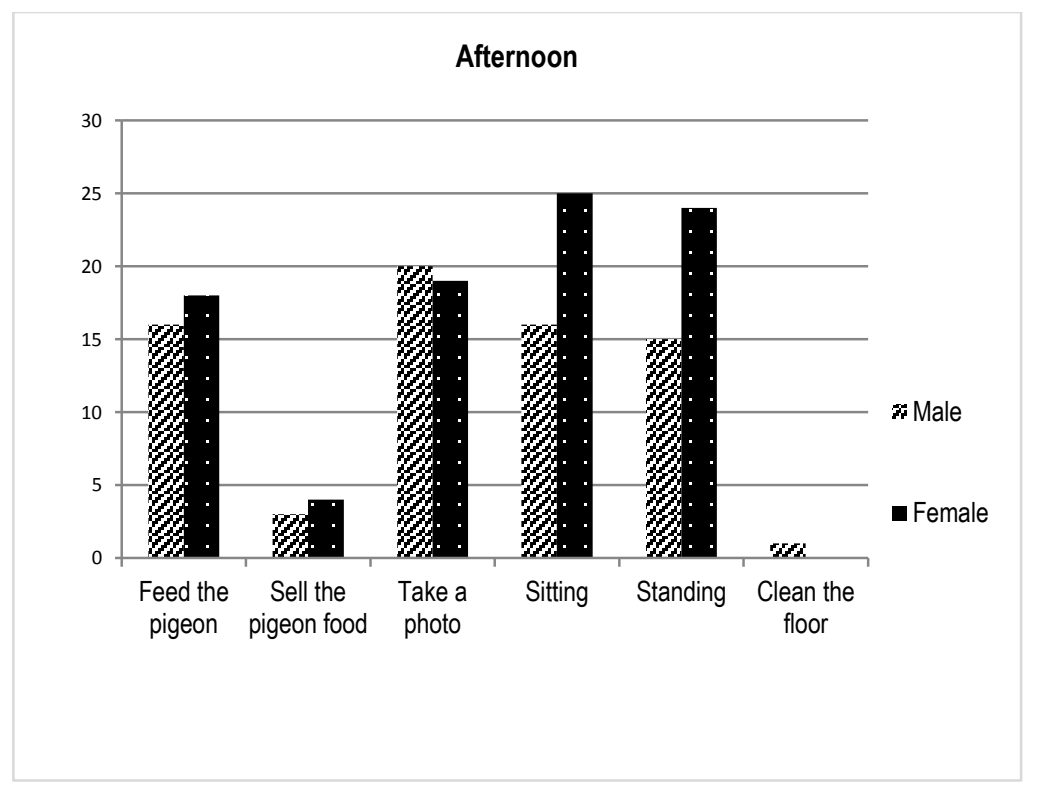

Fig.8: Diagram of afternoon usage from 12.00 p.m.- 02.59 p.m.

The chart shows that from 12.00 - 14.59, there was 161 users, 71 males, and 90 females, the most done activity is taking the photo then resting and feeding pigeons respectively. The full duration is around 14.00 . There was no particular activity at this period due to the hot weather and had the lowest users in this period.

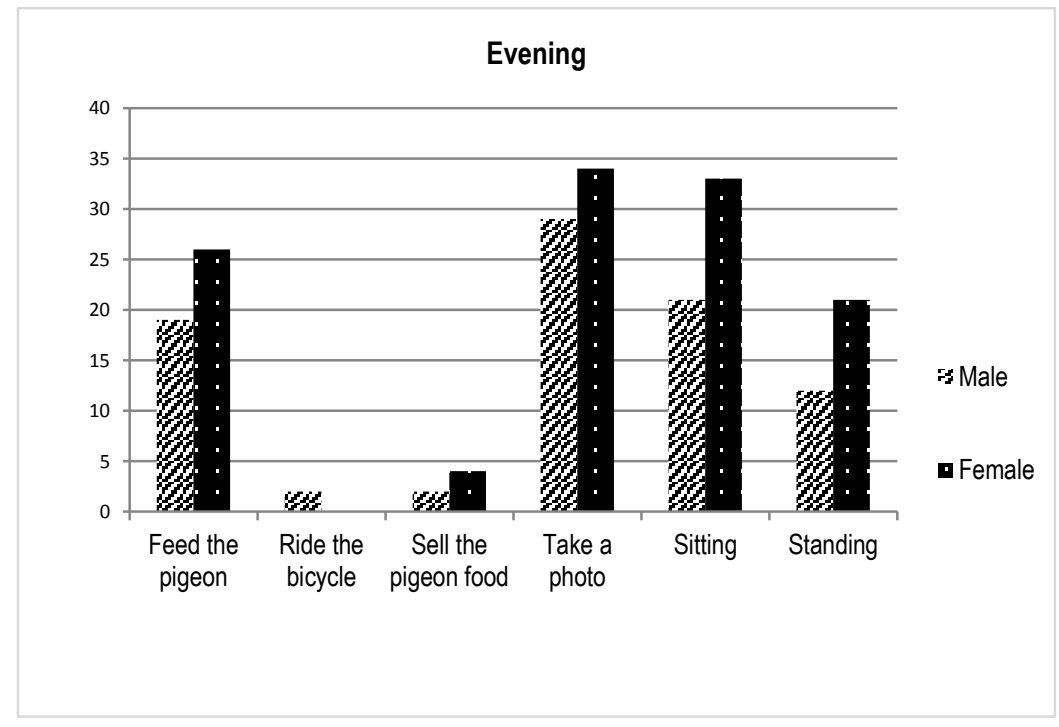

Fig.9: Diagram of evening usage from 3.00 p.m.- 06.00 p.m.

The chart shows that from 15.00 - 18.00, there was 203 users, 85 males, and 118 females, the most done activity is taking a photo, feeding pigeons and resting. The most used period is around 17.00. Special events such as pre-wedding photo and bicycle rider's assembling sometimes happened. In the evening, the sun is not too bright as in the afternoon, so the tourists prefer to do the activity at this time. However, the limitation of evening activity because the sun is going to dawn. The number of user in the plaza decreases obviously. The more it is late, the action will change to walking and sitting more than taking a picture. 


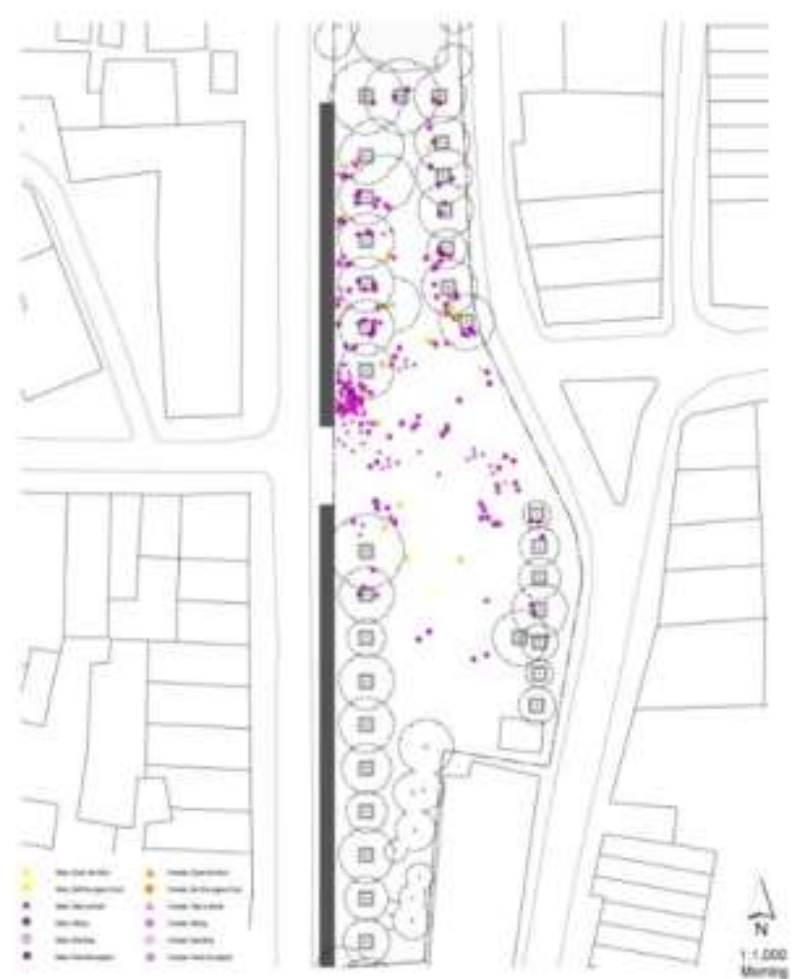

Fig.10: Result of the morning by ArcGIS10.1

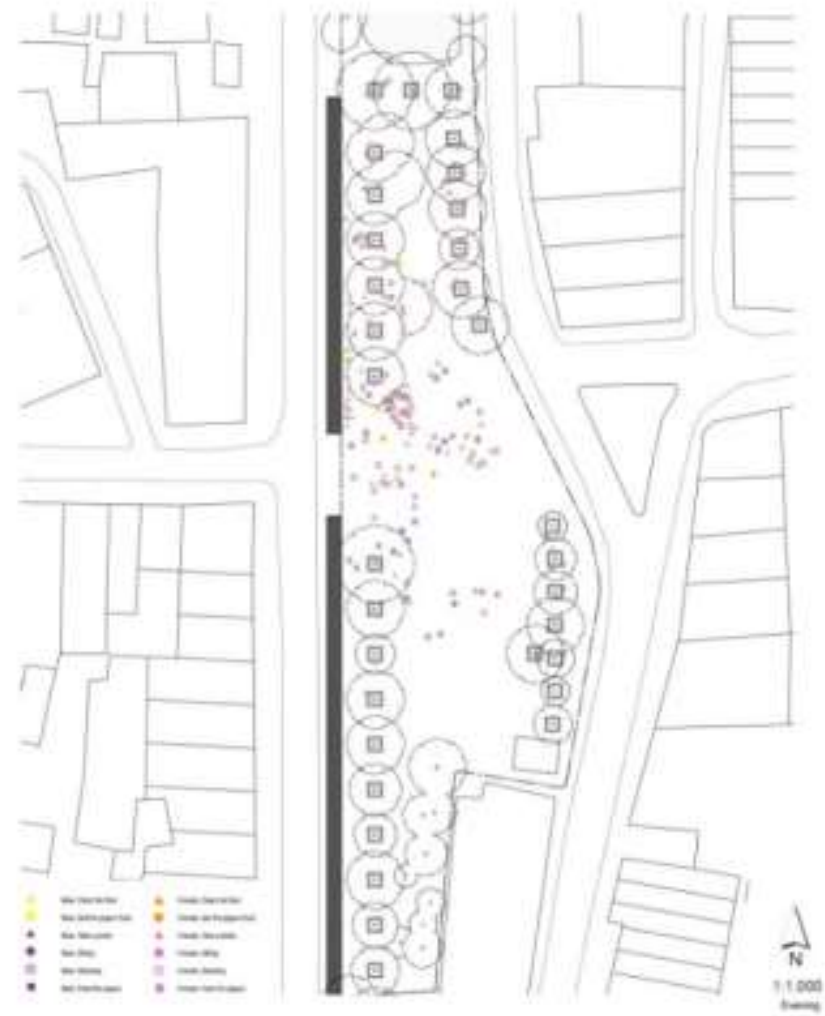

Fig.12: Result of the evening by ArcGIS10.1

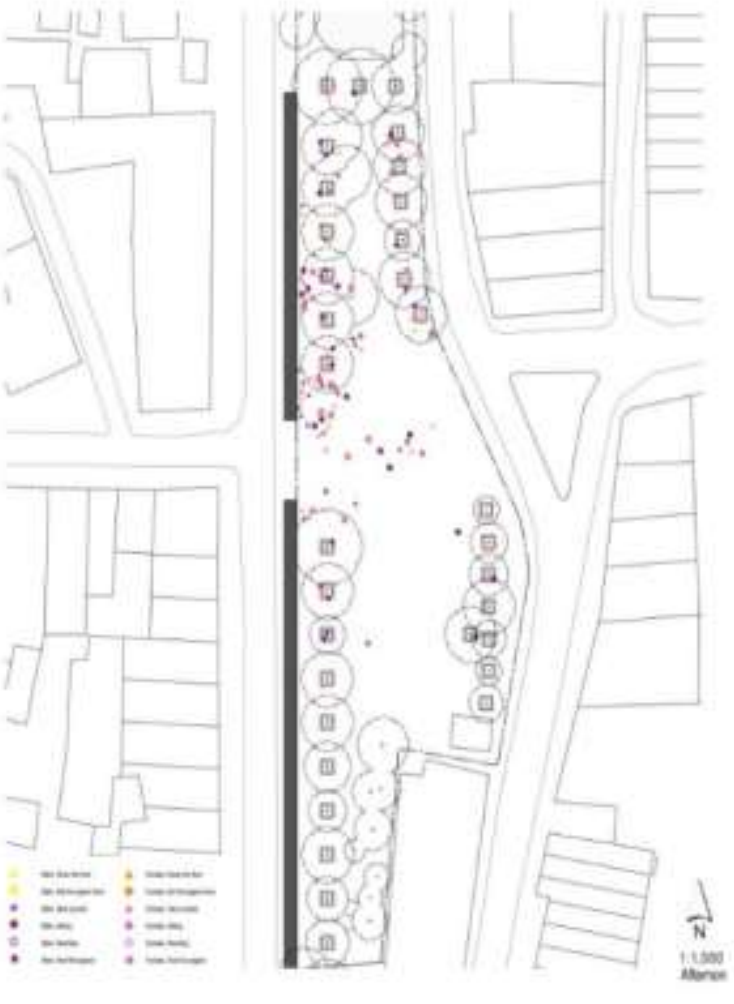

Fig.11: Result of Afternoon by ArcGIS10.1

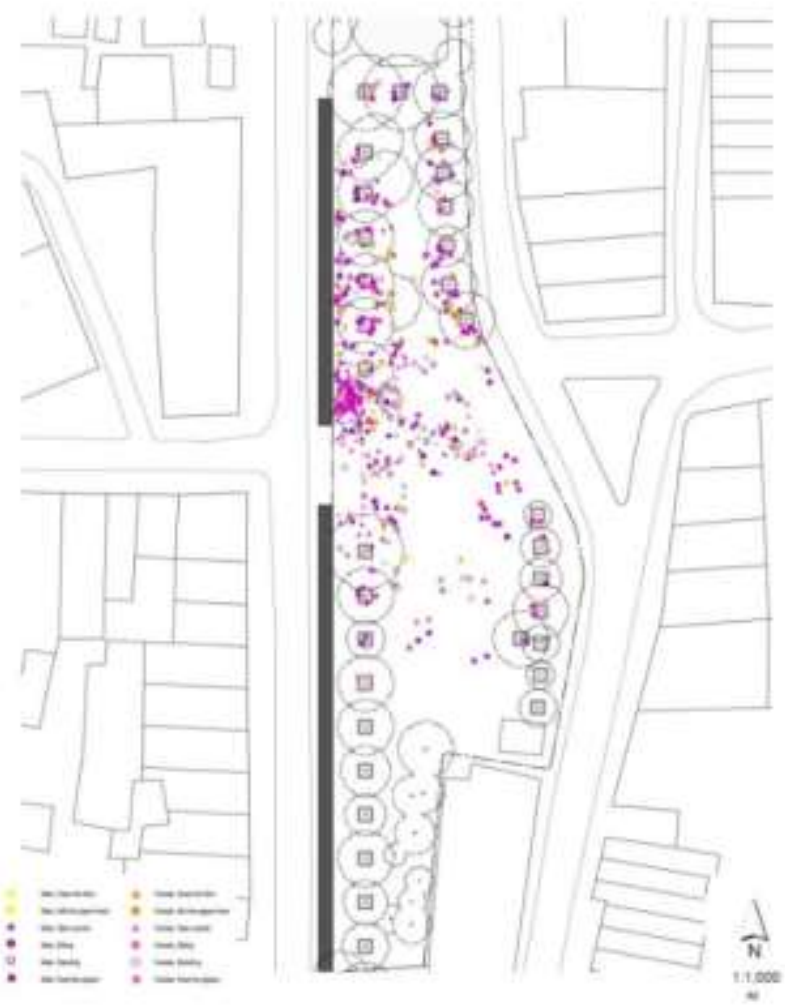

Fig.13: Result per one day by ArcGIS10.1 
As the results above, it can be concluded that the activities that happened at Tha Phae Gate have come from the tourists especially Chinese's tourists, which are, taking the photo at 27 percent, relaxing 25 percent, and feeding pigeons 20 percent. Special activities such as pre-wedding photo, ride the motorcycle and bicycle sometimes happened.

Table 2: The total of activities

\begin{tabular}{lc}
\hline \multicolumn{1}{c}{ Activities } \\
\hline Feed the pigeon & $20 \%$ \\
Take a photo & $27 \%$ \\
Sitting & $25 \%$ \\
Standing & $20 \%$ \\
Ride the bicycle & $2 \%$ \\
Sell the pigeon food & $4 \%$ \\
Ride the motorcycle * & $1 \%$ \\
Clean the floor & $1 \%$ \\
Pre-wedding * & $1 \%$ \\
\hline
\end{tabular}

\subsection{Discussion}

\subsection{Result from Geographic Information System: GIS}

According to the observation of user behavior in the public court using GIS, it revealed that the program beneficially decreased the time of working process as the process had planned and the data can collect completely; therefore, ARCGIs10.1 could process data rapidly. However, the working process of the program is that it will handle by geographic location. For this reason, it required carefulness in collecting site locations of users as a mean to prevent errors. The first problem found by the author is when the author created the map and used the information from Chiang Mai's town and country planning to add locations in ArcGIS10.1 program, later formed the table for processing.

The result from the researching process by the GIS system shows that the program can reduce the processing time by using The ArcGIS 10.1 program as processor details as follow,

- Each type of activities can be divided easily with universal symbols which cannot be done by the camera. It makes any behavioral differences prominent.

- Information collected in layers which can be chosen to display individually or collapse which cannot solve with a camera. However, the pro is that it can use as desired.

- Reduce processing time and can collect information completely, easily accessible and editable.

ArcGIS is a complete, scalable geographic platform and improves planning, design, and development for urban design. The GIS system still has some limitation, even the results can be displayed individually, but the weather condition always cannot be included and need to be collected separately.

According to this research, to apply Geographic Information System (GIS) is for the observation of user behavior at the public space. The Tha Phae gate in Chiang Mai province as the site for study, it was found that as the field study with the use of ArcGIS10.1, this is an alternative way to do a research due to the fact that it is a tool that shortens working time and provides accurate result, resulting in using the result as the reference. Uniquely, to observe user behavior which consists of several activities, this program can classify types of occupations without limit by replacing the symbols and demonstrate the result on the real site referred from GEO code. Additionally, it also allows the user to schedule the time to present the result as the author designed the type of data collection or applied for further research.

Even the survey result shows that there are users at Tha Phae Gate all day, but the researcher interested in the different number of users in each period and reason matters to each activity. 


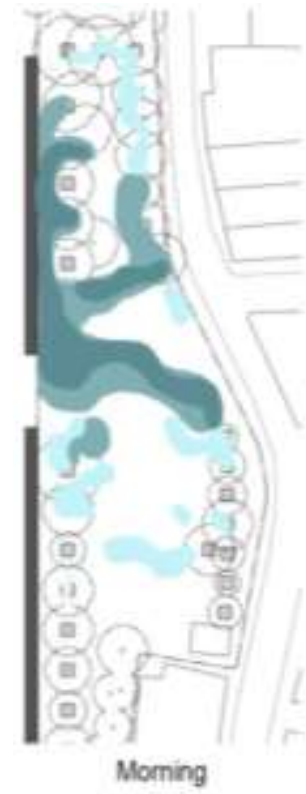

Moming

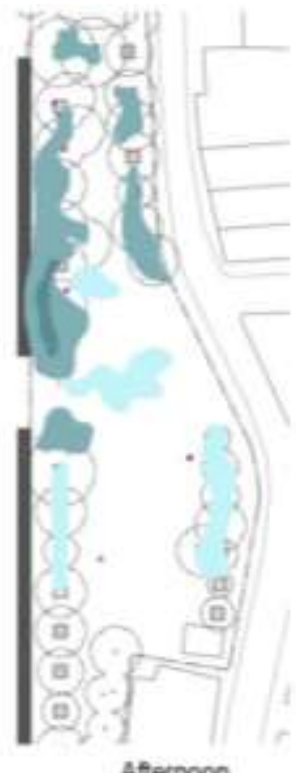

Afternoon

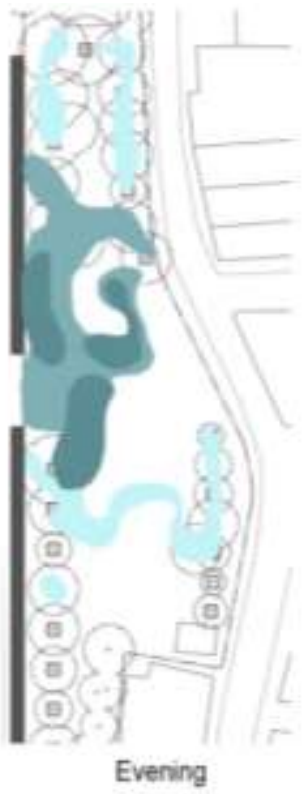

Density

Fig.15: Result of users density at Tha Phae Gate, Chiang Mai, Thailand

Tha Phae gate has an open space across the city canal into Chiang Mai old town. It is wide open space, so sunlight and temperature directly affect to the behavior of users as Fig:15, the photo shows that users choose to stay under the tree because of its shading and more relaxing. Tha Phae Gate is one of the public space to support activities of the city because this site is an open public space which allows people access and join activities

The result of users density at Tha Phae Gate, Chiang Mai, Thailand shows that even each period have a similar number of users, but the factors affect the usage is time and period. In the morning is the period which has the highest number of users especially between $9.30-10.30$ due to the weather that is not too hot. So that the users tend to be using the area at that time. The most done activity is taking a photo then resting and feeding pigeons respectively. Then they go to have lunch or walk to another place nearby.

In the afternoon, sunlight and temperature affect the number of users. At this time, there has a fewer number of users than the morning and evening. The main activity is resting under the tree. The number of users will be increased again around 14.00 which can also state that this period is the gap between groups of users.

In the evening, the sunlight will not be too strong which make some of the users choose to come to the area at this period. According to the main activities which are taking photos and feeding pigeons, the evening period will have conditions with the light. The most obvious thing is that the more extended hour passed, the activity will change to be resting instead.

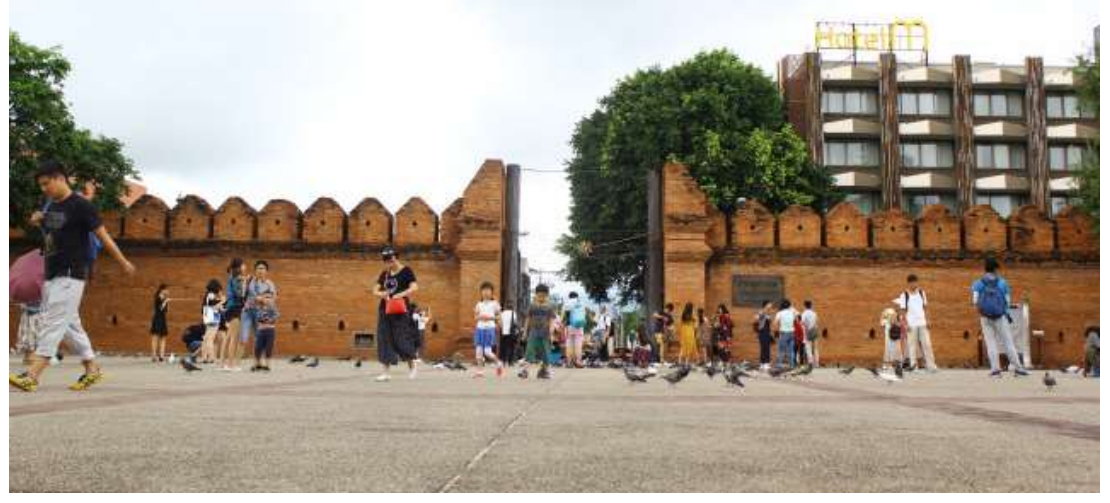

Fig.16: Tha Phae Gate, Chiang Mai, Thailand 


\subsection{Conclusion \& Recommendations}

This research uses the GIS system in behavioral research at the Tha Phae gate area. The result shows that the information gathered with ArcGIS 10.1 program is one of the efficient research methods because it can reduce processing time and generate exact results. The result from this method can be used in future research especially the behavioral study which has various type of activities. This program can divide unlimited activities by symbols and display the result with the geographic coordinates. GEO code can also specify the period in a result chosen to display and can be adapted to use in future research.

The ArcGIS 10.1 is a program to generate and geophysical survey which has a complex application. It can use for various kind of operation which makes the researchers need to study and adapt to appropriately. If the researchers lack understandings of the program, it can be limitations of the program usage. Besides the presentation, in case that the study area plan elaborates, the researcher recommends the AutoCAD program instead because the ArcGIS 10.1 used for setting the coordinates to analyze which often has errors which will affect the overall results.

The result from ArcGIS 10.1 can display behavioral usage of the public yard divided by gender and period to show the difference to use in a comparison process. Other than that, the information can be chosen to display wholly or periodically, reduce processing time and the data will be collected systematically (Marušić, 2012). The results can be helpful to the referencing and analyzing the process of public yard usage in a different period and time.

The benefit of GIS for further research is the flexibility to apply to many fields of studies. For example, urban designers need to consider the street furniture that fits the public plaza usages. Besides the construction techniques; lighting and drainage, the data from GIS can display the occupied space. In the case of the Tha Phae gate area, the existing spatial fitting is very few. The Tha Phae plaza shows a vacant and bold hardscape. This situation is very suitable to analyze the behavior of users because they select the area for their activity by themselves, no effect from the designed furniture.

The cons of the GIS, at first, is the cost. GIS is costly software. For this study, the researcher used a free trial version of ArcGIS 10.1 to demonstrate the process and to evaluate the application under the fundamental questions that have been determined ArcGIS before running the operation. Other cons of GIS are concerned about a person. GIS is not a friendly and easy program. It needs the expert to run. The mistakes from personal causes, for examples; are the mistake of input the fact of data, the decision to create layers and the failure of the complex command language.

\section{Acknowledgment}

The authors would like to thank the generosity in funding from The Thailand Research Fund: Master Research Grants, the scholarships from the Graduate School of Chiang Mai University and the scholarships from the Master of Architecture (Program in Architecture), Faculty of Architecture, Chiang Mai University.

\section{References}

Bunnarong, S. (2017). The Application of Geographic Information System for Construction Management. The Journal of KMUTNB, 21, 52-60.

Carr, S., Francis, M., Rivlin, L. G. \& Stone, A. M. (1992). Public Space. Cambridge: Cambridge University Press. New York: The Press Syndicate of The University of Cambridge.

Charles, A. (2017). Case Study Japan: GIS-technologies in Urban Planning. The World Economic Forum Report: The Future of Urban Development \& Services: Urban Development, 21.

Dantzig, G. \& Saaty, T. L. (1973). Compact City: A Plan for a Livable Urban Environment. San Francisco: W.H. Freeman.

Jirakajohnkool, S. (2008). Learn Geographic Information System by ArcGIS. Bangkok: S.R. Printing Mass Product Company.

Nasr, M. R. (2007). Open Source Software: The Use of Open Source GIS Software and its Impact on Organizations. Middlesex University.

Madanipour, A. (1996). Design of Urban Space: an inquiry into socio-spatial process. New York: John Wiley \& son.

Mahawan, N. (2018). The Application of Geographic Information System for Urban Design in Bangkok Case Study Bang Ruk District, Pathum Wan District, Ratchathewi District, and Phaya Thai District. King Mongkut's Institute of Technology Ladkrabang. Bangkok.

Marušić,B.G.\& Marušić, D.(2012). Behavioral Maps and GIS in Place Evaluation and Design. Application of Geographic Information Systems, 115-138.

Pushkarev,B. S. \& Zupan, J. M. (1975). Urban Space for Pedestrians. Cambridge: MIT Press. 
Sitachitta, P. (2007). Applications of Geographic Information System-GIS for Database Development of the Historic Buildings and Structures in the Municipality of Phuket. Journal of Architectural / Planning Research and Studies, 5, 27-40.

Yupparaj Wittayalai School. (2005). Phra Barami PokKlao, 100 years of Yupparaj Wittayalai, The Granted Title. Chiang Mai: Yupparaj Wittayalai School. 